\title{
Produksi Semen Segar (Volume dan Konsentrasi) dan Beku dari Sapi Pejantan dengan Skor Kondisi Tubuh (SKT) yang Berbeda
}

\author{
Production of Fresh (Volume, Concentration) and Frozen Semen from Bulls \\ with Different Body Condition Scores (BCS) \\ Rasyidah Mappanganro \\ Jurusan Ilmu Peternakan Fakultas Sains dan Teknologi, UIN Alauddin Makassar \\ Gowa-92113, Sulawesi Selatan, Indonesia \\ Korespondensi E-Mail: rasyidah.mappanganro@uin-alauddin.ac.id
}

\begin{abstract}
ABSTRAK
Tujuan penelitian ini yaitu untuk mengetahui produksi semen segar, konsentrasi spermatozoa dan produksi semen beku (straw) dari sapi pejantan dengan skor kondisi tubuh (SKT) yang berbeda, serta SKT pejantan yang ideal untuk dijadikan sebagai produsen semen yang baik. Bangsa sapi yang digunakan adalah bali, limosin, simmental dan brahman yang memiliki SKT sedang (4-5), optimum (6-7) dan gemuk (8-9). Data yang diambil adalah produksi semen segar (evaluasi secara makroskopis dan mikroskopis) dan semen beku. Metode koleksi semen yang dilakukan yaitu menggunakan vagina buatan dengan frekuensi koleksi semen 1-2 kali dalam sepekan. Variabel yang diamati dalam penelitian ini adalah (1) Produksi semen segar dengan melakukan evaluasi kualitas semen segar secara makroskopis (volume), (2) Evaluasi spermatozoa secara mikroskopis (konsentrasi), dan (3) Produksi semen beku dalam jumlah straw yang dihasilkan. Data dianalisis menggunakan analisis variansi general linier model dan dilanjutkan uji beda nyata jujur (uji Tukey). Kesimpulan penelitian ini yaitu Skor kondisi tubuh berpengaruh sangat nyata terhadap produksi semen segar (volume), konsentrasi spermatozoa, dan berpengaruh nyata terhadap produksi semen beku pejantan dengan SKT optimum memiliki produksi semen segar, konsentrasi spermatozoa, dan produksi semen beku tertinggi kemudian diikuti oleh SKT gemuk dan sedang.
\end{abstract}

Kata kunci: Produksi Semen Segar, semen beku, Skor Kondisi Tubuh

\begin{abstract}
The purpose of this study was to determine the production of fresh semen, the concentration of spermatozoa and the production of frozen semen (straw) from bulls with different body condition scores (BCS), and the ideal bulls BCS to be a good semen producer. The cattle breeds used are bali, limosin, simmental and brahman which have moderate BCS (4-5), optimum (6-7) and fat (8-9). The data taken were fresh semen production (macroscopic and microscopic evaluation) and frozen semen. The semen collection method used was using an artificial vagina with a semen collection frequency of 1-2 times a week. The variables
\end{abstract}


observed in this study were (1) fresh semen production by evaluating the quality of fresh semen by macroscopic (volume), (2) microscopic evaluation of spermatozoa (concentration), and (3) production of frozen semen in the number of straws produced. The data were analyzed using the general linear model analysis of variance and continued with the honestly significant difference test (Tukey's test). The conclusion of this study is that the body condition score has a very significant effect on fresh semen production (volume), spermatozoa concentration, and has a significant effect on frozen semen production and moderate.

Keywords: Fresh Semen Production, frozen semen, Body Condition Score

\section{PENDAHULUAN}

Upaya untuk meningkatkan populasi sapi ditempuh beberapa langkah atau tahapan kegiatan yaitu melalui peningkatan angka kelahiran, penggemukan ternak, dan kombinasi antara kenaikan angka kelahiran dan intensifikasi penggemukan serta program terobosan menekan angka kematian, mengendalikan pemotongan betina produktif dan peningkatan produktivitas melalui pengembangbiakan dengan pejantan unggul (Intensifikasi Kawin Alam/INKA) dan Inseminasi Buatan (IB).

Kemampuan reproduksi sapi merupakan faktor yang sangat menentukan perkembangan populasi ternak. Upaya yang dilakukan untuk meningkatkan populasi adalah melalui teknologi Inseminasi Buatan (IB) yang diterapkan pada peternakan rakyat. Dengan IB peternak tidak perlu memelihara sapi pejantan sehingga kemungkinan terjadinya inbreeding dapat dihindari. Namun, IB dapat merugikan peternak akibat peternak dalam melakukan deteksi birahi pada betina kurang akurat dan inseminator kurang terampil.

Inseminasi Buatan (IB) adalah penyampaian atau deposisi semen ke dalam saluran reproduksi betina dengan bantuan alat-alat buatan manusia. Program IB merupakan suatu cara perkawinan yang lebih efisien dan efektif dalam penggunaan semen pejantan unggul untuk membuahi sapi betina dalam jumlah banyak dibandingkan dengan perkawinan alam.

Semen segar merupakan sekresi organ reproduksi jantan yang diejakulasikan dan dapat dikoleksi kemudian dibekukan untuk keperluan IB (Suzanna, 2002). Sebelum dibekukan kualitas semen segar harus dievaluasi terlebih dahulu. Tujuan pembekuan adalah agar semen dapat disimpan lama, sehingga semen dapat dimanfaatkan pada saat diperlukan melalui Inseminasi Buatan (IB). Di samping itu, keuntungan menggunakan semen beku ialah dapat mengatasi hambatan waktu dan jarak, sehingga dapat disediakan kapan dan di mana saja. Namun, rendahnya kualitas semen dan tidak optimalnya teknik penanganan semen 
beku yang digunakan, kondisi reproduksi sapi betina, serta manajemen ternak dan ketrampilan inseminator merupakan faktor yang menghambat keberhasilan IB (Herdis, 1998).

Keberhasilan suatu program IB yaitu mutu semen beku sapi. Mutu semen beku harus selalu terjaga agar fertilitasnya tetap baik. Semen beku yang berkualitas mempunyai persentase motilitas dan Spermatozoa hidup yang tinggi. Kualitas semen yang baik harus dimiliki oleh pejantan sehingga tingkat fertilitas yang tinggi dapat diharapkan. Demi menghindari penggunaan pejantan dengan tingkat fertilitas rendah sebaiknya dilakukan penilaian skor kondisi tubuh (SKT) untuk mengetahui tingkat ketebalan lemak sebelum ternak jantan dipilih menjadi pejantan. Kekurangan maupun kelebihan lemak pada pejantan dapat menyebabkan terganggunya proses spermatogenesis. Hal ini disebabkan karena lemak berperan sebagai bahan penyusun hormon reproduksi seperti testosteron dan estrogen. Hormon steroid tersebut diproduksi oleh testis dan ovarium, memiliki sifat lipolifik (larut dalam lemak) sehingga dibawa di dalam darah menggunakan komplek globulin pengikat (Saryono, 2009).

SKT merupakan penilaian yang berbasis pada kondisi tubuh sapi yang menjadi salah satu alat manajemen bagi penentu performan reproduksi sapi dan menggambarkan kondisi kegemukan secara relatif dari kelompok sapi melalui penggunaan skala 1-9. SKT 1 merupakan kondisi tubuh sapi sangat kurus, SKT 5-7 merupakan kondisi tubuh sapi dengan skor sedang hingga optimum, sementara SKT 9 merupakan kondisi sapi yang sangat berlemak dan gemuk (Parish et al., 2008). Nilai SKT sapi pejantan berhubungan dengan kemampuan reproduksi, dan dapat dipergunakan untuk membuat suatu keputusan manajemen pemeliharaan calon pejantan sebagai sumber semen segar dan beku. Penelitian ini bertujuan untuk mengetahui : 1) Produksi semen segar, konsentrasi spermatozoa dan produksi semen beku (straw) dari sapi pejantan dengan skor kondisi tubuh (SKT) yang berbeda. 2) SKT pejantan yang ideal untuk dijadikan sebagai produsen semen yang baik. 


\section{METODE PENELITIAN}

\section{Lokasi, Materi, dan Metode Pengambilan Data}

Penelitian ini dilaksanakan di Unit Pelaksanaan Teknis Dinas Inseminasi Buatan dan Produksi Semen (UPTD IB) Puca, Kab. Maros, Dinas Peternakan dan Kesehatan Hewan Propinsi Sulawesi Selatan dan Balai Besar Inseminasi Buatan Singosari Jawa Timur.

Jenis penelitian ini adalah kuantitatif dengan metode deskriptif, materi yang digunakan dalam penelitian ini adalah catatan produksi (recording) pejantan dewasa dengan umur 4-5 tahun. Pengambilan catatan dalam penelitian ini menggunakan metode "purposive sampling" yaitu pengambilan sampel catatan secara sengaja berdasarkan berbagai pertimbangan.

Catatan produksi yang diambil dari 12 ekor pejantan dengan bangsa yang berbeda serta SKT yang berbeda. Adapun bangsa yang ditentukan adalah bali, limosin, simmental dan brahman yang memiliki SKT sedang (4-5), optimum (6-7) dan gemuk (8-9) . Data yang diambil adalah produksi semen segar (evaluasi secara makroskopis dan mikroskopis) dan semen beku. Metode koleksi semen yang dilakukan di UPTD Inseminasi Buatan Puca yaitu menggunakan vagina buatan/tiruan dengan frekuensi koleksi semen 1- 2 kali dalam sepekan.

Variabel yang diamati dalam penelitian ini adalah (1) Produksi semen segar dengan melakukan evaluasi kualitas semen segar secara makroskopis (volume), (2) Evaluasi spermatozoa secara mikroskopis (konsentrasi), dan (3) Produksi semen beku dalam jumlah straw yang dihasilkan.

\section{Analisis Data}

Data dianalisis menggunakan analisis variansi General Linier Model dan dilanjutkan uji Beda Nyata Jujur (Uji Tukey) (Steel dan Torrie, 1993). General linear model (GML) memiliki fungsi untuk membandingkan tiga ataupun lebih sampel penelitian berbentuk analisis varian dua arah (two - way anova). Uji Tukey digunakan untuk membandingkan seluruh pasangan rata-rata perlakuan setelah uji Analisis Ragam dilakukan.

Dua buah populasi dikatakan memiliki rata-rata yang berbeda, jika selisih antara rata-rata contoh lebih besar dari nilai BNJ (atau nilai HSD). Nilai BNJ untuk menentukan apakah menolak $\mathrm{H} 0: \mu \mathrm{i}=\mu \mathrm{j}$ di peroleh menggunakan formula: 


$$
\begin{aligned}
& \mathrm{BNJ}=\text { tukey } \alpha_{\alpha ; p ; d b=E r r o r} \frac{1}{\sqrt{2}} \sqrt{K T G\left(\frac{1}{n i}+\frac{1}{n j}\right)} \\
& \mathrm{ni}=\text { ukuran contoh ke-i; } \\
& n j=u k u r a n \text { contoh ke-j }
\end{aligned}
$$

\section{HASIL DAN PEMBAHASAN}

\section{Volume Semen}

Berdasarkan pengumpulan data yang telah dilakukan, maka diperoleh hasil sebagai berikut:

Tabel 1. Rataan Volume Semen Segar antar Bangsa

\begin{tabular}{lc}
\hline Bangsa & Volume Semen $(\mathrm{ml})$ \\
\hline Bali & $4,60 \pm 1,69^{\mathrm{a}}$ \\
Limousin & $5,82 \pm 1,58^{\mathrm{b}}$ \\
Simmental & $5,94 \pm 1,54^{\mathrm{b}}$ \\
Brahman & $7,20 \pm 2,04^{\mathrm{c}}$ \\
Total rataan & $5,89 \pm 1,94$ \\
\hline
\end{tabular}

Ket : Superskrip yang berbeda pada kolom yang sama menunjukkan adanya perbedaan yang nyata $(\mathrm{P}<0,05)$ dan sangat nyata $(\mathrm{P}<0,01)$.

Tabel 1. di atas dapat dilihat bahwa hasil rata-rata volume semen pada sapi bali, limousin, simmental, dan brahman adalah 4,60, 5,82, 5,94, dan 7,20ml. Dari rataan volume semen tersebut tidak terdapat perbedaan yang nyata $(P>0,05)$ antara bangsa sapi simmental dengan limousin. Pejantan bangsa bali dengan brahman memiliki perbedaan volume yang sangat nyata $(\mathrm{P}<0,01)$ yaitu $4,60 \mathrm{ml}$ dan $7,20 \mathrm{ml}$. Terdapat perbedaan yang nyata $(\mathrm{P}<0,05)$ antara pejantan bangsa bali dengan limousin, bali dengan simmental, limousin dengan brahman, dan simmental dengan brahman. Volume semen terbanyak dihasilkan oleh sapi Brahman yaitu 7,20 $\mathrm{ml}$ dan yang paling rendah adalah sapi bali 4,60 ml.

Tabel 2. menunjukkan perbedaan rataan volume semen pada SKT yang berbeda. Dari hasil uji Tukey, terdapat perbedaan yang nyata $(\mathrm{P}<0,05)$ antara SKT sedang (5-6) dengan optimum (6-7), dan sedang (5-6) dengan gemuk (8-9). Sedangkan SKT optimum dengan gemuk tidak terdapat perbedaan yang nyata $(P>0,05)$. Volume semen terbanyak dihasilkan oleh sapi yang memiliki SKT optimum (6-7) yaitu 6,36 $\mathrm{ml}$ dan yang paling sedikit adalah SKT sedang (5-6) dengan volume semen yang dihasilkan adalah 5,19 ml. Pejantan dengan SKT gemuk (8-9) menghasilkan rataan volume semen sebanyak 6,12 ml. 
Tabel 2. Rataan Volume Semen Segar pada SKT yang berbeda

\begin{tabular}{llc}
\hline SKT & Bangsa & Volume Semen $(\mathrm{ml})$ \\
\hline \multirow{3}{*}{ Sedang } & Bali & $3,76 \pm 1,15$ \\
$(4-5)$ & Limousin & $4,93 \pm 1,69$ \\
& Simmental & $4,59 \pm 1,23$ \\
& Brahman & $4,94 \pm 1,70$ \\
Optimum & Total & $5,19 \pm 1,87 \mathrm{a}$ \\
$(6-7)$ & Bali & $4,06 \pm 1,10$ \\
& Limousin & $6,31 \pm 1,10$ \\
& Simmental & $7,25 \pm 1,30$ \\
Gemuk & Brahman & $7,81 \pm 3,01$ \\
$(8-9)$ & Total & $6,36 \pm 2,26 \mathrm{~b}$ \\
& Bali & $5,96 \pm 1,90$ \\
& Limousin & $7,46 \pm 1,01$ \\
& Simmental & $6,00 \pm 0,74$ \\
& Brahman & $6,34 \pm 1,52$ \\
& Total & $6,12 \pm 1,45 . \mathrm{b}, \mathrm{c}$ \\
\hline
\end{tabular}

Ket: Superskrip yang berbeda pada kolom yang sama menunjukkan berbeda nyata $(\mathrm{P}<0,05)$

Volume semen terdiri atas dua komponen yakni spermatozoa dan plasma semen (Perry,1968). Spermatozoa merupakan sel pembawa genetik yang diproduksi oleh testis dan dipengaruhi oleh hormon-hormon gonadotropin serta androgen (Rizal dan Herdis, 2008). Plasma semen merupakan sumber nutrisi bagi spermatozoa untuk hidup yang dihasilkan oleh kelenjar vesikularis (Taylor dan Bogart, 1988).

Volume semen segar dilakukan dengan membaca angka pada tabung penampungan semen. Volume dapat juga digunakan dalam menentukan jumlah sperma per ejakulasi bila dikalikan dengan konsentrasi (Lestari, 2013).

Berdasarkan hasil penelitian dapat diketahui bahwa volume semen segar sapi bali, limosin dan simmental dan brahman memiliki rata rata-rata volume 5,89 ml, volume ini menunjukan kisaran yang normal. Tabel 1. menunjukkan rataan volume semen antara bangsa sapi simmental dengan limousin perbedaan yang nyata $(\mathrm{P}>0,05)$. Pejantan bangsa bali dengan brahman memiliki perbedaan volume yang sangat nyata $(\mathrm{P}<0,01)$ yaitu $4,60 \mathrm{ml}$ dan $7,20 \mathrm{ml}$. Terdapat perbedaan yang nyata $(\mathrm{P}<0,05)$ antara sapi pejantan bali dengan 
limousin, bali dengan simmental, limousin dengan brahman, dan simmental dengan brahman. Hal ini tidak sejalan dengan pendapat Sumeidiana et al., (2007), bahwa antar bangsa sapi, rata-rata volume semen menunjukkan perbedaan yang tidak nyata.

Berdasarkan perbedaan SKT, hasil uji lanjut Tukey (beda nyata jujur) menunjukkan bahwa terdapat perbedaan yang nyata $(\mathrm{P}<0,05)$ antara SKT sedang $(5-6)$ dengan optimum (6-7), dan sedang (5-6) dengan gemuk (8-9). Sedangkan SKT optimum dengan gemuk tidak terdapat perbedaan yang nyata $(\mathrm{P}>0,05)$. Volume semen terbanyak dihasilkan oleh sapi yang memiliki SKT optimum (6-7) yaitu 6,36 $\mathrm{ml}$ dan yang paling sedikit adalah SKT sedang (5-6) dengan volume semen yang dihasilkan adalah 5,19 ml. Pejantan dengan SKT gemuk (89) menghasilkan rataan volume semen sebanyak 6,12 $\mathrm{ml}$. Hal tersebut menandakan bahwa SKT mempengaruhi produksi semen segar yaitu berupa volume yang dihasilkan, baik SKT sedang (4-5), optimum (6-7), dan gemuk (8-9). Syamyono et al. (2014) menambahkan bahwa produksi spermatozoa dan sekresi cairan plasma semen disebabkan oleh tingginya kadar testosteron yang menyebabkan volume semen ikut meningkat. Saryono (2009) menyatakan bahwa tinggi rendahnya kadar testosteron dipengaruhi oleh jumlah lemak yang mengalami proses steroidogenesis. Dari hasil analisis statistik diketahui bahwa volume semen yang paling banyak dihasilkan ada pada SKT optimum (6-7) dan bangsa sapi berpengaruh sangat nyata $(\mathrm{P}<0,01)$ terhadap volume semen yang dihasilkan.

Banyaknya jumlah atau volume semen yang diejakulasikan oleh sapi pejantan juga sangat bergantug pada frekuensi ejakulasi, hal ini seperti yang dinyatakan oleh Yendraliza (2008) bahwa banyaknya jumlah atau volume semen yang diejakulasikan oleh sapi pejantan juga sangat bergantug pada frekuensi ejakulasi, hal ini seperti yang dinyatakan oleh Yendraliza (2008) bahwa Pemakaian pejantan dalam satu satuan waktu perlu dibatasi mengingat hasil-hasil pengamatan bahwa frekuensi ejakulasi yang terlampau sering dalam satuan waktu yang relatif pendek cenderung untuk menurunkan libido, volume semen dan jumlah spermatozoa per-ejakulasi. Ternak jantan yang belum dewasa harus dibatasi pemakaiannya karena penurunan kualitas semen yang di hasilkan, dan dapat terjadi penurunan libido.

\section{Konsentrasi Spermatozoa}

Hasil penelitian pada perbedaan rataan konsentrasi spermatozoa sapi pejantan pada bangsa yang berbeda disajikan pada Tabel 3. berikut ini. 
Tabel 3. Perbedaan Rataan Konsentrasi Spermatozoa antar Bangsa

\begin{tabular}{lc}
\hline Bangsa & Konsentrasi (juta/ml) \\
\hline Bali & $1.995,29 \pm 348,46^{\mathrm{a}}$ \\
Limousin & $963,04 \pm 275,40^{\mathrm{b}}$ \\
Simmental & $1.008,58 \pm 208,99 \mathrm{~b}$ \\
Brahman & $1.000,75 \pm 202,58^{\mathrm{b}}$ \\
Total rataan & $1.241,92 \pm 509,65$ \\
\hline
\end{tabular}

Ket : Superskrip yang berbeda pada kolom yang sama menunjukkan perbedaan sangat nyata $(\mathrm{P}<0,01)$

Tabel 3. Menunjukkan perbedaan konsentrasi spermatozoa pada bangsa sapi bali, limousin, simmental dan brahman secara berturut-turut yaitu 1.995,29, 963,04, 1.008,58, 1000,75 juta/ml. Terdapat perbedaan yang sangat nyata $(\mathrm{P}<0,01)$ antara bangsa bali dengan ketiga bangsa lainnya yaitu limousin, simmental dan brahman. Rataan konsentrasi spermatozoa pada sapi limousin dengan simmental dan brahman tidak terdapat perbedaan yang nyata $(P>0,05)$ dengan nilai $P=0,93$ dan 0,96 . Begitu juga dengan sapi brahman dengan simmental, keduanya tidak memiliki perbedaan yang nyata $(\mathrm{P}>0,05)$ dengan nilai $\mathrm{P}=1,00$. Konsentrasi spermatozoa terbanyak ada pada sapi bali dengan jumlah 1.995,29 juta/ml sedangkan yang paling rendah pada sapi limousin dengan konsentrasi sebesar 964,04 juta/ml.

Tabel 4. menunjukkan perbedaan rataan konsentrasi spermatozoa pada SKT yang berbeda. Terdapat perbedaan yang nyata $(\mathrm{P}<0,05)$ antara SKT sedang $(5-6)$ dengan optimum (6-7). Sedangkan SKT optimum dengan gemuk tidak terdapat perbedaan yang nyata $(\mathrm{P}>0,05)$ begitupun dengan SKT sedang dan gemuk. Konsentrasi spermatozoa terbanyak dihasilkan oleh sapi yang memiliki SKT optimum (6-7) yaitu 1.334,06 juta/ml dan yang paling sedikit adalah SKT sedang (5-6) dengan konsentrasi spermatozoa yang dihasilkan adalah 1.152,06 juta/ml. Pejantan dengan SKT gemuk (8-9) memiliki rataan konsentrasi spermatozoa sebanyak 1.239,63 juta/ml.

Terdapat perbedaan yang sangat nyata $(\mathrm{P}<0,01)$ antara bangsa bali dengan ketiga bangsa lainnya yaitu limousin, simmental dan brahman. Rataan konsentrasi spermatozoa pada sapi limousin dengan simmental dan brahman tidak terdapat perbedaan yang nyata $(P>0,05)$, begitu juga dengan sapi brahman dengan simmental, keduanya tidak memiliki perbedaan yang nyata $(\mathrm{P}>0,05)$. Hal ini sesuai dengan penelitian Sumeidiana et al., (2007) dimana rata-rata konsentrasi spermatozoa antar bangsa sapi tidak berbeda nyata. Konsentrasi spermatozoa terbanyak ada pada sapi bali dengan jumlah 1.995,29 juta/ml 
sedangkan yang paling rendah pada sapi limousin dengan konsentrasi sebesar 964,04 juta/ml.

Tabel 4. Perbandingan Rataan Konsentrasi Spermatozoa Pada Setiap SKT yang berbeda

\begin{tabular}{llc}
\hline SKT & Bangsa & Konsentrasi (juta/ml) \\
\hline Sedang & Bali & $1.966,32 \pm 326,47$ \\
& Limousin & $763,50 \pm 139,57$ \\
Simmental & $869,63 \pm 283,02$ \\
Brahman & $1.008,63 \pm 187,52$ \\
Total & $1.152,06 \pm 539,00$ a \\
Optimum & Bali & $2.138,50 \pm 392,02$ \\
& Limousin & $1.208,88 \pm 174,86$ \\
& Simmental & $1.036,63 \pm 117,12$ \\
Brahman & $952,25 \pm 158,12$ \\
Temuk & Total & $1.334,06 \pm 530,89 \mathrm{~b}$ \\
& Bali & $1.880,88 \pm 315,19$ \\
& Limousin & $916,75 \pm 286,56$ \\
& Simmental & $1.119,50 \pm 112,50$ \\
& Brahman & $1.041,38 \pm 264,63$ \\
& Total & $1.239,63 \pm 454,46$ a,b
\end{tabular}

Ket : Superskrip yang berbeda pada kolom yang sama menunjukkan perbedaan nyata $(\mathrm{P}<0,05)$

Konsentrasi spermatozoa dari ketiga bangsa yang relatif sama kemungkinan disebabkan oleh metode koleksi, frekuensi ejakulasi, dan prestimulasi yang sama. Menurut Salisbury dan VanDemark (1985), konsentrasi spermatozoa akan mengikuti kedewasaan dan perkembangan seksual, kualitas pakan yang diberikan, besar testes, kesehatan alat reproduksi, umur dan frekuensi ejakulasi pejantan.

Hasil penelitian menunjukkan rataan konsentrasi spermatozoa dari keempat bangsa tersebut adalah berkisar 1.241,92 $\pm 509,65 \mathrm{juta} / \mathrm{ml}$. Hal ini sesuai dengan pernyataan Garner dan Hafez (2000), bahwa konsentrasi spermatozoa sekitar 800-2.000 juta/ml dan menurut Campbell et al., (2003) bahwa pada sapi jantan dewasa konsentrasi spermatozoa berkisar antara $800-1.200 \mathrm{juta} / \mathrm{ml}$.

Hasil penelitian yang diperoleh menunjukkan bahwa pejantan dengan SKT sedang (4) menghasilkan volume semen terendah, tetapi konsentrasi spermatozoa yang dihasilkan tinggi. Hal tersebut sesuai dengan pernyataan Bearden dan fuquay 1980, menyatakan bahwa 
berat badan dan besar badan mempunyai korelasi positif dengan produksi spermatozoa secara kuantitas. Toelihere (1981) menyatakan bahwa semen sapi cenderung memiliki volume yang rendah dengan konsentrasi yang tinggi. Konsentrasi sperma yang cenderung tinggi dipengaruhi oleh genetis individu untuk menghasilkan sperma berkonsentrasi tinggi dengan volume yang rendah (Sumeidiana et al., 2007). Lebih lanjut dijelaskan oleh Salisbury dan VanDemark (1985) bahwa konsentrasi semen banyak dipengaruhi oleh umur, variasi individu, pakan, besar testes dan perkembangan seksual. Demikian pula yang diungkapkan Vandeplassche (1982) dan Toelihere (1993) bahwa kekurusan maupun kegemukan pada ternak merupakansalah satu faktor pengganggu aktivitas reproduksi.

\section{Produksi Semen Beku}

Tabel 5. Menunjukkan perbedaan produksi semen beku pada bangsa sapi bali, limousin, simmental dan brahman secara berturut-turut yaitu 195,75, 220,13, 228,54 dan 278,83 straw. Terdapat perbedaan yang nyata $(\mathrm{P}<0,05)$ antara bangsa bali dengan brahman. Rataan produksi straw pada sapi bali dengan limousin dan simmental tidak terdapat perbedaan yang nyata $(\mathrm{P}>0,05)$ dengan nilai $\mathrm{P}=0,80$ dan 0,60 . Begitu juga dengan sapi limousin dengan simmental dan brahman tidak memiliki perbedaan yang nyata $(P>0,05)$. Jumlah produksi straw terbanyak terdapat pada sapi brahman dengan jumlah 278,83 straw sedangkan yang paling rendah pada sapi bali dengan produksi sebesar 195,75 straw.

Tabel 5. Perbedaan Rataan Produksi Semen Beku (Straw) pada Bangsa Sapi yang Berbeda

\begin{tabular}{lc}
\hline Bangsa & Produksi Semen Beku (straw) \\
\hline Bali & $195,75 \pm 85,72$ a \\
Limousin & $220,13 \pm 103,22 \mathrm{a}, \mathrm{b}$ \\
Simmental & $228,54 \pm 72,64 \mathrm{a}, \mathrm{b}$ \\
Brahman & $278,83 \pm 103,60 \mathrm{~b}$ \\
Rataan & $230,81 \pm 95,70$ \\
\hline
\end{tabular}

Ket : Superskrip yang berbeda pada kolom yang sama menunjukkan perbedaan nyata $(\mathrm{P}<0,05)$

Tabel 6. Memperlihatkan perbedaan rataan produksi semen beku (straw) sapi pejantan pada SKT yang berbeda. Terdapat perbedaan yang sangat nyata $(\mathrm{P}<0,01)$ antara SKT sedang (5-6) dengan optimum (6-7) dan perbedaan yang nyata $(\mathrm{P}<0,05)$ antara SKT sedang dengan gemuk (8-9). Sedangkan SKT optimum dengan gemuk tidak terdapat 
perbedaan yang nyata $(\mathrm{P}>0,05)$. Produksi semen beku (straw) yang terbanyak dihasilkan oleh sapi yang memiliki SKT optimum (6-7) yaitu 273,62 straw dan yang paling sedikit adalah SKT sedang (5-6) dengan jumlah straw yang dihasilkan adalah 183,06. Pejantan dengan SKT gemuk (8-9) memiliki rataan produksi semen beku sebanyak 235,75 straw.

Tabel 6. Rataan Produksi Semen Beku pada SKT yang Berbeda

\begin{tabular}{lll}
\hline Bangsa & SKT & Produksi Semen (straw) \\
\hline Sedang & Bali & $157,50 \pm 61,19$ \\
$(4-5)$ & Limousin & $143,50 \pm 63,32$ \\
& Simmental & $142,75 \pm 41,15$ \\
& Brahman & $288,50 \pm 74,36$ \\
& Total & $183,06 \pm 85,09$ a \\
Optimum & Bali & $221,75 \pm 87,83$ \\
$(6-7)$ & Limousin & $292,50 \pm 78,20$ \\
& Simmental & $286,38 \pm 38,16$ \\
& Brahman & $293,88 \pm 134,81$ \\
Gemuk & Total & $273,62 \pm 92,14 \mathrm{~b}$ \\
$(8-9)$ & Bali & $208,00 \pm 100,40$ \\
& Limousin & $224,38 \pm 110,28$ \\
& Simmental & $256,60 \pm 32,61$ \\
& Brahman & $254,13 \pm 102,44$ \\
& Total & $235,75 \pm 89,80 \mathrm{~b}$
\end{tabular}

Ket : Superskrip yang berbeda pada kolom yang sama menunjukkan perbedaan nyata $(\mathrm{P}<0,05)$ dan sangat nyata $(\mathrm{P}<0,01)$

Hasil penelitian menunjukkan bahwa rata-rata produksi semen beku antara bangsa tidak berbeda nyata $(\mathrm{P}>0,05)$, semen beku yang dihasilkan dari setiap bangsa relatif sama (Tabel 2). Hafez (1993) menyatakan bahwa faktor umur sangat mempengaruhi produksi semen yang dihasilkan oleh pejantan, rata-rata umur sapi yang digunakan untuk penelitian kisaran 4-5 tahun yang telah mencapai umur dewasa.

Hasil penelitian menunjukkan bahwa terdapat pengaruh yang nyata $(\mathrm{P}<0,05)$ SKT dalam bangsa terhadap produksi semen beku. Hal tersebut menandakan bahwa SKT mempengaruhi produksi semen beku yaitu dengan jumlah straw yang dihasilkan, baik SKT sedang (4-5), optimum (6-7), dan gemuk (8-9). Hasil pengamatan menunjukkan bahwa total straw yang dihasilkan per ejakulasi adalah 230 straw. 
Berdasarkan hasil uji analisis statistik diketahui bahwa SKT berpengaruh sangat nyata $(\mathrm{P}<0,01)$ terhadap produksi semen beku. Produksi semen beku yang dihasilkan oleh setiap individu tidak dipengaruhi oleh produksi semen segar yang tinggi. Hal tersebut mungkin disebabkan oleh proses pembekuan yang melalui beberapa tahap, seperti pernyataan Wahyu (2008) bahwa setelah semen terkoleksi maka akan dilakukan pemeriksaan terhadap kualitas semen segar antara lain: (1) secara makroskopis, meliputi volume semen (rata-rata 5 $\mathrm{ml}$ ), warna semen (susu, krem dan kuning), kekentalan semen (encer, sedang dan kental) dan $\mathrm{pH}(6,2-6,8)$ atau rata-rata $\mathrm{pH}=7$. (2) Secara mikroskopis, meliputi gerakan massa, gerak individu, motilitas (minimal 70\%) dan selanjutnya, pemeriksaan konsentrasi semen dengan menggunakan spektrofotometer. Semen beku yang diproduksi telah memenuhi syarat SNI 4869.1:2008 yaitu semen beku sapi dikemas dalam bentuk straw dengan ukuran ministraw volume 0,25 ml dengan jumlah sel spermatozoa minimal 25 juta (SNI, 2008).

Perbedaan produksi semen segar antara SKT dapat disebabkan oleh pemanfaatan cadangan energi yang disimpan dalam tubuh, menurut Anggorodi (1990) sapi dengan kondisi tubuh yang baik cadangan energi digunakan untuk aktivitas reproduksi setelah memenuhi kebutuhan hidup pokok dan produksi. Pejantan dengan SKT optimum memanfaatkan cadangan energi di dalam tubuh untuk reproduksi setelah memenuhi kebutuhan hidup pokok dan produksi karena memiliki nilai yang tinggi dibandingkan dengan SKT sedang dan SKT gemuk.

\section{KESIMPULAN}

Berdasarkan penelitian yang telah dilaksanakan, maka diperoleh kesimpulan sebagai berikut:

1. Skor kondisi tubuh berpengaruh sangat nyata terhadap produksi semen segar (volume), konsentrasi spermatozoa, dan berpengaruh nyata terhadap produksi semen beku

2. Pejantan dengan SKT optimum memiliki produksi semen segar, konsentrasi spermatozoa, dan produksi semen beku tertinggi kemudian diikuti oleh SKT gemuk dan sedang. 


\section{DAFTAR PUSTAKA}

Anggorodi, R. 1990. Ilmu Makanan Ternak Umum. Gramedia, Jakarta.

Campbell, J. R., Campbell, K.L., dan Kenealy, M.D. 2003. Artificial Insemination. In Animal Sciences $4^{\text {th }}$ ed. Mc Graw-Hill, New York.

Djanuar, D. 2008. Mengenal Inseminasi Buatan. Cv. Simple, Jakarta

Garner, D.L. and Hafez, E.S.E. 2000. Spermatozoa and Seminal Plasma. in :B. Hafez dan E. S. Chapter 7. Reproduction in Farm Animals, 7th Edition. Lippicont Williams and Wilkins.

Hafez E.S.E. 1993. Anatomy of Male Reproduction. In. E.S.E Hafez (Ed). Reproduction in Farm Animals. Sixth Edition, Lea and Febiger, Philadelphia.

Herdis. 1998. Metode Pemberian gliserol dan lama ekuilibrasi pada proses pembekuan semen kerbau lumpur. Tesis. Program Pascasarjana Institut Pertanian Bogor, Bogor.

Lestari S., Saleh, D. M., dan Maidaswar. 2013. Profil Kualitas Semen Segar Sapi Pejantan Limousin Dengan Umur Yang Berbeda Di Balai Inseminasi Buatan Lembang Jawa Barat. Jurnal Ilmiah Peternakan 1(3): 1165 -1172

Parish, J.A. dan Rhinehart, J.D. 2008. Body Condition Scoring of Beef Cattle. Mississipi State University. United States.

Perry, E. J . 1968 . The Artificial Insemination of Farm Animals. Rutgers University Press, The State University of New York.

Salisbury, G.W dan N.L. VanDemark. 1985. Fisiologi Reproduksi dan Inseminasi Buatan pada Ternak Sapi. Terjemahan Djanuar. Universitas Gajah Mada Press, Yogyakarta.

Saryono. 2009. Biokimia Hormon. Nuha Medika, Yogyakarta.

SNI (Standar Nasional Indonesia). 2008. Semen Beku - Bagian 1 : Sapi (SNI 4869.1:2008). BSN (Badan Standarisasi Nasional), Jakarta.

Steel, R.G.D. dan Torrie, J.H. 1993. Prinsip dan Prosedur Statistika suatu Pendekatan Biometrik terjemahan B. Sumantri. Gramedia Pustaka Utama, Jakarta.

Sumeidiana, I., Wuwuh, S., dan Mawarti, E. 2007. Volume Semen dan Konsentrasi Sperma Sapi Simmental, Limousin dan Brahman di Balai Inseminasi Buatan Ungaran. Universitas Diponegoro Semarang.

Suzanna, E. 2008. Kaji banding kualitas semen beku sapi potong yang telah didistribusikan ke lapangan. Skripsi. Institut Pertanian Bogor, Bogor.

Taylor, R. E. and Bogart. R. 1988. Scientic Farm Animal Production. 3rded. Macmillan Publishing Company, New York.

Toelihere, M. R. 1981. Ilmu Kemajiran pada Ternak. Fakultas Kedokteran Hewan Institut Pertanian Bogor, Bogor.

Toelihere, M.R. 1993. Inseminasi Buatan pada Ternak. Angkasa, Bandung.

Vandeplassche, M. 1982. Reproductive Efficiency in Cattle : A Guideline for Project in Developing Countries. FAO, Rome.

Wahyu, J. 2008. Manajemen mutu semen beku sapi di balai inseminasi buatan (BIB) Lembang Bandung (Semen Beku Sapi Ongole dan Frisian Holstein). Skripsi. Institut Pertanian Bogor, Bogor.

Yendraliza. 2008. Inseminasi Buatan Pada Ternak. SUSKA Press, Pekanbaru. 